\title{
Penentuan Skala Prioritas Penanganan Ruas Jalan Provinsi Di Kabupaten Purwakarta
}

\author{
Asep Setiawan \\ Fakultas Teknik Universitas Widyatama \\ Email: asepsetiawan@gmail.com
}

\begin{abstract}
The provincial roads maintenance and repair are often constrained by limited budgets, so that the road management priority is generally determined by policy factors, which often cause roads treatment disparity. The purpose of this study was to determine the criteria and sub-criteria, the weights of criteria and sub-criteria, as well as develop a mathematical equation in order to determine to roads handling priority in the area of Purwakarta, West Java. Tha Delphi and Cut Off Point methods were applied to determine the criteria, which result in three criteria selected i.e. road condition, traffic volume and economic factors, respectively. Afterward, the Analytical Hierarchy Process was used to determine the weighting factors for the criteria and sub-criteria. The results for the criteria weights were as follows: the roads conditions had a weighting factor of $67.7 \%$; the traffic volume of $18.3 \%$; and the economi of $13.0 \%$. Based on the criteria and sub-criteria weight, a mathematical equation was develop to define the handling priority of roads in Purwakarta.
\end{abstract}

Keywords: provincial road, handling priority, Cut Off Point

\begin{abstract}
Abstrak. Penanganan ruas jalan provinsi sering terkendala oleh terbatasnya anggaran, sehingga prioritas penanganan ruas jalan umumnya didominasi oleh faktor kebijakan. Kondisi ini sering menyebabkan terjadinya ketimpangan dalam penanganan ruas jalan provinsi. Tujuan dari penelitian ini adalah untuk menentukan kriteria dan sub-kriteria, menentukan bobot kriteria dan sub-kriteria, serta membuat persamaan matematika untuk menentukan urutan prioritas penanganan ruas jalan provinsi di Kabupaten Purwakarta, Jawa Barat. Hasil analisis dengan menggunakan gabungan metode Delphi dengan metode Cut Off Point diperoleh tiga kriteria yaitu faktor kondisi jalan, faktor volume lalu lintas dan faktor ekonomi. Selanjutnya, metode Analytical Hierarchy Process digunakan untuk menentukan bobot kriteria dan sub-kriteria. Dari hasil analisis diperoleh bobot kriteria sebagai berikut: faktor kondisi jalan memiliki bobot $67,7 \%$; volume lalu lintas 18,3\%; dan ekonomi 13,0\%. Berdasarkan bobot kriteria dan sub-kriteria, dihasilkan persamaan matematika untuk menentukan urutan prioritas penanganan ruas jalan provinsi di Kabupaten Purwakarta.
\end{abstract}

Kata Kunci : jalan provinsi, prioritas penanganan, Cut Off Point

\section{A. PENDAHULUAN}

Jalan provinsi di Kabupaten Purwakarta mengalami kerusakan yang disebabkan oleh beberapa faktor antara lain konstruksi jalan, faktor muatan jalan yang melebihi kapasitas, dan faktor pembiayaan pembuatan jalan. Terkait dengan anggaran jalan provinsi, anggaran Rp 1 Triliun yang ditetapkan dalam APBD tahun 2015 masih terasa belum memadai. Pasalnya anggaran yang dialokasikan tersebut harus pula dikurangi dengan anggaran gaji pekerja. APBD mengalokasikan lebih dari $10 \%$ untuk perbaikan infrastruktur jalan, dan 
hal tersebut pun masih belum sebanding dengan panjang jalan di Jawa Barat.

Keterbatasan anggaran tersebut menyebabkan prioritas penanganan jaringan jalan lebih didominasi oleh faktor kebijakan yang lebih berdasarkan pada aspek. Kondisi ini sering menyebabkan terjadinya ketimpangan dalam penanganan jalan. Berkaitan dengan hal tersebut perlu dilakukan suatu studi skala prioritas penanganan ruas jalan provinsi di Kabupaten Purwakarta dengan metode yang tepat agar dapat membantu para pengambil kebijakan dalam menentukan prioritas sesuai dengan kebutuhan dan manfaatnya yang melibatkan semua stakeholders.

Tujuan dari penelitian ini adalah untuk memilih kriteria dan sub kriteria yang sesuai dengan menggunakan kombinasi metode Delphi dengan metode Cut off Point, menentukan nilai bobot kriteria dan sub kriteria dengan menggunakan metode Analitycal Hierarcy Process (AHP), serta membuat persamaan matematis untuk menetapkan urutan prioritas penanganan ruas jalan pada jaringan jalan provinsi di Kabupaten Purwakarta.

\section{B. KAJIAN PUSTAKA}

\section{Klasifikasi Jalan Berdasarkan Statusnya}

Pengelompokan jalan dimaksudkan untuk mewujudkan kepastian jalan berdasarkan wewenang pembinaan jalan. Menurut Peraturan Pemerintah No.26 Tahun 1985 tentang Jalan, pengelompokan jalan adalah sebagai berikut:

a. Jalan Nasional adalah jalan yang menghubungkan antar ibukota provinsi, yang memiliki kepentingan strategis terhadap kepentingan nasional di bawah pembinaan menteri atau pejabat yang ditunjuk.

b. Jalan Provinsi adalah jalan di bawah pembinaan provinsi atau instansi yang ditunjuk, di antaranya adalah jalan kolektor primer yang menghubungkan ibukota provinsi dengan ibukota kabupaten/kotamadya.

c. Jalan Kabupaten adalah jalan di bawah pembinaan kabupaten atau instansi yang ditunjuk.

d. Jalan Kotamadya adalah jalan di bawah pembinaan kotamadya, di antaranya jalan kota dan sekunder dalam kota.

e. Jalan Desa adalah jalan di bawah pembinaan desa yaitu jalan sekunder yang ada di desa.

f. Jalan Khusus adalah jalan di bawah pembinaaan pejabat atau instansi yang ditunjuk yaitu jalan yang dibangun secara khusus oleh instansi atau kelompok.

\section{Penanganan Jalan}

Penanganan jalan menurut PP No. 34 Tahun 2006 tentang Jalan adalah kegiatan yang merupakan bagian dari penyelenggaraan pembangunan jalan yang mencakup penetapan rencana tingkat kinerja yang akan dicapai serta perkiraan biaya yang diperlukan. Di dalam Penjelasan PP No 34 Tahun 2006 tentang Jalan disebutkan bahwa program penanganan jaringan jalan meliputi program pemeliharaan jalan, program peningkatan jalan, dan program konstruksi jalan baru. Pengelolaan jalan lebih memfokuskan pada kegiatan pemeliharaan berkala (periodic maintenance) dan peningkatan strukturnya (betterment). Penanganan jalan yang ditinjau pada penelitian ini adalah program pemeliharaan jalan dan peningkatan jalan, tidak termasuk program konstruksi jalan baru. 


\section{METODE PENELITIAN}

\section{Metode Pengumpulan Data}

Dalam penelitian ini terdapat 3 tahap pengumpulan data, yaitu:

a. Pengumpulan Data Tahap 1

b. Pengumpulan Data Tahap 1 bertujuan untuk memilih kriteria dan sub kriteria. Pengumpulan data dilakukan dengan melakukan wawancara terhadap reponden yang mengerti masalah penanganan ruas jalan provinsi dan kriteria-kriteria yang diteliti.

c. Pengumpulan Data Tahap 2

Pengumpulan Data Tahap 2 bertujuan untuk memilih kriteria model. Pengumpulan data berupa data primer dengan melakukan kuesioner terhadap responden expert yang dianggap mengerti masalah penanganan ruas jalan provinsi dan kriteria-kriteria yang diteliti.

d. Pengumpulan Data Tahap 3

Pengumpulan Data Tahap 3 bertujuan untuk menentukan bobot kriteria dan sub kriteria dengan menggunakan metode AHP. Pengumpulan data berupa data primer dengan melakukan kuesioner terhadap responden expert.

\section{Metode Pengolahan Data}

Metode yang digunakan untuk mengolah data pada penelitian ini adalah kombinasi metode Delphi dengan metode Cut Off Point, serta metode AHP.

\section{HASIL PENELITIAN DAN PEMBAHASAN}

\section{Pemilihan Kriteria dan Sub Kriteria}

Pemilihan kriteria dan sub kriteria diawali dengan melakukan wawancara putaran 1 dan wawancara putaran 2 kepada 8 (delapan) responden expert yang berasal dari unsur pemerintah, yaitu dari Dinas Bina Marga Provinsi Jawa Barat sebanyak 2 responden, Dinas Bina Marga \& Pengairan Kabupaten Purwakarta sebanyak 2 responden, Bappeda Provinsi Jawa Barat sebanyak 2 responden, dan Bappeda Kabupaten Purwakarta sebanyak 2 responden. Selanjutnya dilakukan wawancara dan diskusi sebanyak 2 putaran, kemudian disusun rekapitulasi pendapat dari seluruh responden seperti pada Tabel 1.

Tabel 1 Kriteria dan Sub Kriteria

\begin{tabular}{|c|c|c|}
\hline No. & Kriteria & Sub Kriteria \\
\hline 1. & $\begin{array}{l}\text { Kondisi } \\
\text { Jalan }\end{array}$ & $\begin{array}{l}\text { Lubang-lubang, Legokan } \\
\text { /Amblas, Retak-retak, } \\
\text { Alur Bekas Roda, } \\
\text { Kemiringan } \\
\text { Drainase }\end{array}$ \\
\hline 2. & $\begin{array}{l}\text { Volume } \\
\text { Lalu } \\
\text { Lintas }\end{array}$ & $\begin{array}{l}\text { Truk } 6 \text { Sumbu, Truk } 5 \\
\text { Sumbu, Truk } 4 \text { Sumbu, } \\
\text { Truk } 3 \text { Sumbu, Bus, } \\
\text { Mobil Penumpang, } \\
\text { Sepeda Motor }\end{array}$ \\
\hline 3. & $\begin{array}{l}\text { Tata Guna } \\
\text { Lahan }\end{array}$ & $\begin{array}{lr}\text { Kawasan } & \text { Industri, } \\
\text { Kawasan } & \text { Pertanian, } \\
\text { Kawasan } & \text { Pariwisata, } \\
\text { Kawasan Pelayanan dan } \\
\text { Pemukiman, Kawasan } \\
\text { Lindung }\end{array}$ \\
\hline 4. & $\begin{array}{l}\text { Kepadatan } \\
\text { Penduduk }\end{array}$ & $\begin{array}{l}\text { Kepadatan Tinggi, } \\
\text { Kepadatan Sedang, } \\
\text { Kepadatan Rendah }\end{array}$ \\
\hline 5. & Ekonomi & $\begin{array}{l}\text { Manfaat, Estimasi Biaya } \\
\text { Proyek }\end{array}$ \\
\hline 6. & $\begin{array}{l}\text { Kebijakan } \\
\text { Eksekutif }\end{array}$ & $\begin{array}{l}\text { - Musrenbang } \\
\text { Kecamatan } \\
-\quad \text { Musrenbang } \\
\text { Kabupaten } \\
-\quad \text { Musrenbang } \\
\text { Provinsi Anggaran Biaya } \\
-\quad \text { Tambahan }\end{array}$ \\
\hline
\end{tabular}

\section{Pemilihan Kriteria dan Sub Kriteria Model}

Menurut Maggie dan Tummala (2001) bahwa metode untuk menentukan 
tingkat kepentingan dari kriteria adalah dengan menggunakan Metode Cut off. Tahapan ini diawali dengan penyebaran kuesioner kepada 12 (dua belas) responden yaitu dari Dinas Bina Marga Provinsi Jawa Barat sebanyak 4 responden, Dinas Bina Marga \& Pengairan Kabupaten Purwakarta sebanyak 2 responden, Bappeda Provinsi Jawa Barat sebanyak 4 responden, dan Bappeda Kabupaten Purwakarta sebanyak 2 responden. Rekapitulasi jawaban responden terhadap kriteria diperlihatkan pada Tabel 2 .
Berdasarkan nilai Cut Off Point di atas, maka Kriteria Tata Guna Lahan, Kepadatan Penduduk, dan Kebijakan Eksekutif harus dikeluarkan dari kriteria model karena nilai rata-ratanya kurang dari 2,042 dan dianggap ketiga kriteria tersebut kurang penting dalam penentuan prioritas penanganan ruas jalan provinsi di Kabupaten Purwakarta, dengan demikian kriteria model yang akan digunakan adalah faktor kondisi jalan, faktor volume lalu lintas, dan faktor ekonomi.

Tabel 2. Rekapitulasi Jawaban Responden Terhadap Kriteria

\begin{tabular}{|l|l|l|l|l|l|l|l|}
\hline Kriteria & $\begin{array}{l}\text { Tidak } \\
\text { Penting } \\
(\mathbf{a})\end{array}$ & $\begin{array}{l}\text { Penting } \\
(\mathbf{b})\end{array}$ & $\begin{array}{l}\text { Sangat } \\
\text { Penting } \\
(\mathbf{c})\end{array}$ & $\begin{array}{l}\text { Skor } \\
\text { Total } \\
(\mathbf{d})\end{array}$ & $\begin{array}{l}\text { Total } \\
\text { Kuesioner } \\
(\mathbf{e})\end{array}$ & $\begin{array}{l}\text { Skor Rata- } \\
\text { rata } \\
(\mathbf{f})\end{array}$ & Ket. \\
\hline Kondisi Jalan & 2 & 0 & 10 & 32 & 12 & 2.667 & Nilai \\
\hline Volume Lalu Lintas & 1 & 2 & 9 & 32 & 12 & 2.667 & Maks. \\
\hline Tata Guna Lahan & 7 & 5 & 0 & 17 & 12 & 1.417 & $\begin{array}{l}\text { Nilai } \\
\text { Min. }\end{array}$ \\
\hline $\begin{array}{l}\text { Kepadatan } \\
\text { Penduduk }\end{array}$ & 6 & 6 & 0 & 18 & 12 & 1.500 & \\
\hline Ekonomi & 3 & 4 & 5 & 26 & 12 & 2.167 & \\
\hline Kebijakan Eksekutif & 7 & 4 & 1 & 18 & 12 & 1.500 & \\
\hline
\end{tabular}

Perhitungan Skor Total menggunakan Persamaan 1.

Skor Total $(\mathrm{d})=\{(\mathrm{a} \times 1)+(\mathrm{b} \times 2)+(\mathrm{c} \times$ 3) $\}$

Contoh perhitungan untuk Kriteria Kondisi Jalan:

a. $\quad$ Skor Total $(\mathrm{d})$ :

(d) $=(2 \times 1)+(0 \times 2)+(10 \times 3)=32$

b. Skor Rata-Rata (f) $=\frac{d}{e}=\frac{32}{12}=$ 2,667

Nilai Cut Off Point $=\frac{\text { Nilai Maks }+ \text { Nilai Min }}{2}$ (2)

Maka,

Nilai Cut Off Point $=\frac{(2,667+1,417)}{2}=$ 2,042

\section{Bobot Penilaian Kriteria}

Bobot dari masing-masing kriteria dianalisis dengan metode $A H P$ dengan langkah -langkah sebagai berikut:

Langkah 1 Perhitungan Matriks Awal Diawali dengan menganalisis jawaban kuesioner dari 45 orang responden dengan perhitungan kebalikan sesuai dengan matriks perbandingan berpasangan. Data selengkapnya diperlihatkan pada Tabel 3 .

Selanjutnya nilai yang dipakai adalah nilai rata-rata kumulatif tersebut. Besaran matriks masing-masing adalah : Matriks $\mathrm{A}: \mathrm{B}=5,148$ 
Tabel 3 Skala Perbandingan Penilaian Kriteria

\begin{tabular}{|c|c|c|c|c|c|c|c|c|c|c|c|}
\hline \multirow{2}{*}{ Resp. } & \multicolumn{3}{|c|}{ Skala Penilaian } & \multirow{2}{*}{ Resp. } & \multicolumn{3}{|c|}{ Skala Penilaian } & \multirow{2}{*}{ Resp. } & \multicolumn{3}{|c|}{ Skala Penilaian } \\
\hline & $\mathrm{A}: \mathrm{B}$ & $\mathrm{A}: \mathrm{C}$ & $\mathrm{B}: \mathrm{C}$ & & $\mathrm{A}: \mathrm{B}$ & $\mathrm{A}: \mathrm{C}$ & $\mathrm{B}: \mathrm{C}$ & & $\mathrm{A}: \mathrm{B}$ & $A: C$ & $\mathrm{~B}: \mathrm{C}$ \\
\hline 1 & 9,000 & 9,000 & 9,000 & 16 & 6,000 & 6,000 & 3,000 & 31 & 5,000 & 3,000 & 2,000 \\
\hline 2 & 5,000 & 3,000 & 2,000 & 17 & 1,000 & 2,000 & 0,500 & 32 & 5,000 & 5,000 & 1,000 \\
\hline 3 & 5,000 & 3,000 & 2,000 & 18 & 0,500 & 1,000 & 3,000 & 33 & 5,000 & 5,000 & 0,250 \\
\hline 4 & 7,000 & 0,333 & 0,333 & 19 & 5,000 & 3,000 & 2,000 & 34 & 1,000 & 7,000 & 7,000 \\
\hline 5 & 5,000 & 3,000 & 2,000 & 20 & 6,000 & 5,000 & 2,000 & 35 & 1,000 & 1,000 & 1,000 \\
\hline 6 & 5,000 & 4,000 & 2,000 & 21 & 5,000 & 3,000 & 2,000 & 36 & 7,000 & 1,000 & 0,143 \\
\hline 7 & 7,000 & 7,000 & 2,000 & 22 & 8,000 & 5,000 & 3,000 & 37 & 3,000 & 9,000 & 0,333 \\
\hline 8 & 6,000 & 5,000 & 2,000 & 23 & 4,000 & 2,000 & 2,000 & 38 & 7,000 & 3,000 & 0,333 \\
\hline 9 & 0,143 & 0,143 & 0,143 & 24 & 7,000 & 6,000 & 2,000 & 39 & 7,000 & 4,000 & 2,000 \\
\hline 10 & 5,000 & 6,000 & 5,000 & 25 & 4,000 & 4,000 & 2,000 & 40 & 6,000 & 7,000 & 2,000 \\
\hline 11 & 9,000 & 7,000 & 0,143 & 26 & 5,000 & 0,333 & 0,333 & 41 & 6,000 & 0,200 & 0,250 \\
\hline 12 & 7,000 & 5,000 & 1,000 & 27 & 7,000 & 0,333 & 5,000 & 42 & 7,000 & 1,000 & 2,000 \\
\hline 13 & 6,000 & 5,000 & 2,000 & 28 & 4,000 & 6,000 & 6,000 & 43 & 5,000 & 4,000 & 2,000 \\
\hline 14 & 1,000 & 0,333 & 0,200 & 29 & 5,000 & 0,143 & 0,143 & 44 & 7,000 & 5,000 & 2,000 \\
\hline \multirow[t]{3}{*}{15} & 7,000 & 7,000 & 0,143 & 30 & 5,000 & 3,000 & 2,000 & 45 & 3,000 & 7,000 & 0,333 \\
\hline & & & & & & & & $\Sigma \mathrm{R}$ & 231,643 & 173,818 & 87,580 \\
\hline & & & & & & & & $\Sigma \mathrm{R} / 45$ & 5,148 & 3,863 & 1,946 \\
\hline
\end{tabular}

Matriks A:C $=3,863$

Matriks B:C $=1,946$

Sedangkan :

Matriks B:A merupakan kebalikan dari matriks $\mathrm{A}: \mathrm{B}=\frac{1}{(\mathrm{~A}: \mathrm{B})}=\frac{1}{(5,148)}=0,194$

Matriks C:A merupakan kebalikan dari matriks $\mathrm{A}: \mathrm{C}=\frac{1}{(\mathrm{~A}: \mathrm{C})}=\frac{1}{(3,863)}=0,259$

Matriks $\mathrm{C}: \mathrm{B}$ merupakan kebalikan dari matriks $\mathrm{B}: \mathrm{C}=\frac{1}{(\mathrm{~B}: \mathrm{C})}=\frac{1}{(1,946)}=1,514$

Data matriks awal kriteria diperlihatkan pada Tabel 4.

Tabel 4 Matriks Awal Kriteria

\begin{tabular}{|l|l|l|l|}
\hline & A & B & C \\
\hline A & 1,000 & 5,148 & 3,863 \\
\hline B & 0,194 & 1,000 & 1,946 \\
\hline C & 0,259 & 0,514 & 1,000 \\
\hline $\boldsymbol{\Sigma}$ & 1,453 & 6,661 & 6,809 \\
\hline
\end{tabular}

Langkah 2. Perhitungan Nilai Eigen Vektor

Jumlah baris A = Matriks AA x Matriks $\mathrm{AB}$ x Matriks AC

$$
=1,000 \times 5,148 \times 3,863
$$

$=19,883$

Jumlah baris $\mathrm{B}=$ Matriks BA $\mathrm{x}$ Matriks BB xMatriks BC

$$
=0.194 \times 1,000 \times 1,946=
$$

0,378

Jumlah baris $\mathrm{C}=$ Matriks CA $\mathrm{x}$ Matriks CB x Matriks CC

$$
=0,259 \times 0,514 \times 1,000
$$

$=0,133$

Menentukan Besaran wi :

wi $=\sqrt[n]{\text { Jumlah baris }} ;$ dimana $n=3$

Sehingga :

wi baris $A=\sqrt[3]{19,883}=2,709$

Maka : Eigen Vektor $(\mathrm{Xi})=\frac{\mathrm{wi}}{\sum \mathrm{Wi}}==\frac{2,709}{3,943}$ $=0,687$

Data nilai eigen vektor untuk skala penentuan prioritas kriteria diperlihatkan pada Tabel 5. 
Tabel 5 Nilai Eigen Vektor untuk Skala Penentuan Prioritas Kriteria

\begin{tabular}{|c|c|c|c|c|c|c|}
\hline & A & B & $\mathrm{C}$ & $\mathrm{Jml}$ & Wi & $\begin{array}{l}\text { E- } \\
\text { Vektor }\end{array}$ \\
\hline A & $\begin{array}{l}1,00 \\
0\end{array}$ & $\begin{array}{l}5,14 \\
8 \\
\end{array}$ & $\begin{array}{l}3,86 \\
3 \\
\end{array}$ & $\begin{array}{l}19,8 \\
83\end{array}$ & $\begin{array}{l}2,70 \\
9\end{array}$ & 0,687 \\
\hline B & $\begin{array}{l}0,19 \\
4 \\
\end{array}$ & $\begin{array}{l}1,00 \\
0\end{array}$ & $\begin{array}{l}1,94 \\
6 \\
\end{array}$ & $\begin{array}{l}0,37 \\
8\end{array}$ & $\begin{array}{l}0,72 \\
3 \\
\end{array}$ & 0,183 \\
\hline $\mathrm{C}$ & $\begin{array}{l}0,25 \\
9\end{array}$ & $\begin{array}{l}0,51 \\
4\end{array}$ & $\begin{array}{l}1,00 \\
0\end{array}$ & $\begin{array}{l}0,13 \\
3\end{array}$ & $\begin{array}{l}0,51 \\
0\end{array}$ & 0,130 \\
\hline$\Sigma$ & $\begin{array}{l}1,45 \\
3 \\
\end{array}$ & $\begin{array}{l}6,66 \\
1 \\
\end{array}$ & $\begin{array}{l}6,80 \\
9 \\
\end{array}$ & $\begin{array}{l}20,3 \\
94 \\
\end{array}$ & $\begin{array}{l}3,94 \\
3 \\
\end{array}$ & 1,000 \\
\hline
\end{tabular}

Langkah 3. Perhitungan Nilai Eigen Maksimum

Nilai Eigen Maksimum diperoleh dari Matriks Awal dikalikan dengan EVektor masing-masing matriks dan kemudian hasil perkalian tersebut dijumlahkan. Hal ini diperlihatkan pada Gambar 1.

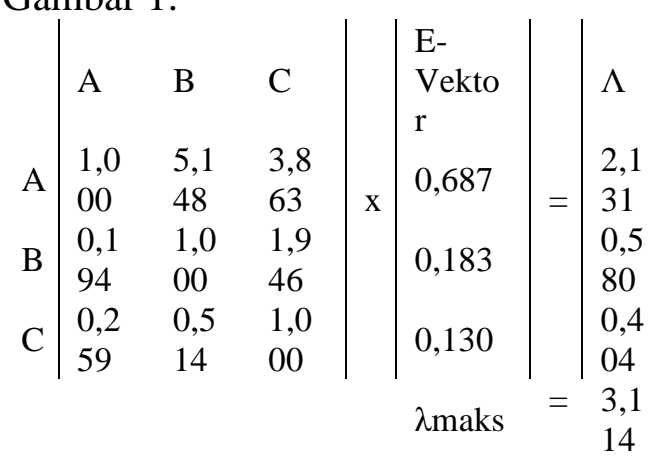

Gambar 1. Matrik Nilai Eigen Maksimum Kriteria

Maka nilai Eigen Maksimum $(\lambda$ maks $)=$ 3,114

Langkah 4. Control terhadap Indeks Konsistensi

Consistency Index $(C I)=\frac{(\lambda m a k s-n)}{(n-1)} ;$ dimana $\mathrm{n}=3$

$C I=\frac{(3,114-3)}{(3-1)}=0,057$

Consistency Ratio $(C R)=\frac{C I}{R I}$, untuk $\mathrm{n}=$ 3 maka $R I=0,58$

Nilai Random Index (RI) untuk setiap ordo matriks diperlihatkan pada Tabel 6.
Tabel 6 Nilai Random Index (RI)

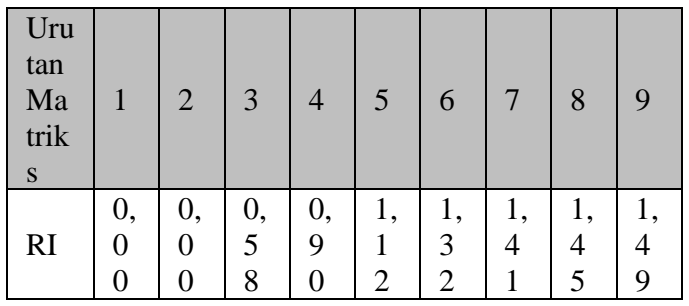

$\mathrm{CR}=\frac{0,057}{0,58}=0,098$

Nilai Consistency Ratio (CR) lebih kecil dari 0,1 maka nilai tersebut sudah sesuai dengan syarat konsistensi yaitu harus lebih kecil dari 0,1 atau $10 \%$.

Langkah 5. Pembobotan Kriteria

Bobot elemen diperoleh dari nilai EVektor yang dinyatakan dalam Persentase seperti diperlihatkan pada Tabel 4.7.

Tabel 7 Bobot KriteriaSkala Prioritas Penanganan Jalan Provinsi

\begin{tabular}{|l|l|}
\hline Kriteria & Bobot (\%) \\
\hline Faktor Kondisi Jalan & 68,7 \\
\hline Faktor Volume Lalu Lintas & 18,3 \\
\hline Faktor Ekonomi & 13,0 \\
\hline \multicolumn{2}{|c|}{ Berdasarkan data pada Tabel 7 }
\end{tabular}

terlihat bahwa kondisi jalan adalah kriteria utama dalam menentukan prioritas penanganan ruas jalan provinsi di Kabupaten Purwakarta dengan bobot $68,7 \%$. Terpilihnya kriteria kondisi jalan sebagai kriteria utama sesuai permintaan masyarakat yang selalu menginginkan jalan yang mantap, serta diharapkan mampu melayani pergerakan manusia dan barang dari tempat asal ke tempat tujuan dengan aman dan nyaman. Selain hal tersebut, kondisi jalan yang baik juga harus diusahakan untuk mencegah terjadinya kecelakaan lalu lintas.

Kriteria volume lalu lintas menempati urutan kedua dengan bobot sebesar 18,3\%; dan terakhir adalah kriteria ekonomi dengan bobot 13,0\%. Faktor volume lalu lintas mempunyai prioritas yang lebih penting bila 
Gambar 2 Struktur Level Hierarki Penanganan Ruas Jalan Provinsi

\begin{tabular}{|c|c|c|c|}
\hline Level I (Tujuan) & Level II (Kriteria) & \multicolumn{2}{|l|}{ Level III (Subkriteria) } \\
\hline & $\begin{array}{c}\text { Faktor Kondisi Jalan } \\
\text { (A) } \\
(0,687)\end{array}$ & $\begin{array}{l}\text { - Lubang-lubang } \\
\text { - Legokan/Amblas } \\
\text { - Retak-retak } \\
\text { - Alur Bekas Roda } \\
\text { - Kemiringan Jalan } \\
\text { - Drainase }\end{array}$ & $\begin{array}{l}\mathrm{a}_{1}(0,363) \\
\mathrm{a}_{2}(0,274) \\
\mathrm{a}_{3}(0,131) \\
\mathrm{a}_{4}(0,080) \\
\mathrm{a}_{5}(0,061) \\
\mathrm{a}_{6}(0,091)\end{array}$ \\
\hline \multirow[t]{2}{*}{$\begin{array}{c}\text { Penentuan Skala } \\
\text { Prioritas Penanganan } \\
\text { Ruas Jalan Provinsi }\end{array}$} & $\begin{array}{l}\text { Faktor Volume } \\
\text { Lalu Lintas }(B) \\
\qquad(0,183)\end{array}$ & $\begin{array}{l}\text { - Truk } 6 \text { Sumbu } \\
\text { - Truk } 5 \text { Sumbu } \\
\text { - Truk } 4 \text { Sumbu } \\
\text { - Truk } 3 \text { Sumbu } \\
\text { - Bus } \\
\text { - Mobil Penumpang } \\
\text { - Sepeda Motor }\end{array}$ & $\begin{array}{l}\mathrm{b}_{1}(0,284) \\
\mathrm{b}_{2}(0,211) \\
\mathrm{b}_{3}(0,160) \\
\mathrm{b}_{4}(0,116) \\
\mathrm{b}_{5}(0,114) \\
\mathrm{b}_{6}(0,073) \\
\mathrm{b}_{7}(0,042)\end{array}$ \\
\hline & $\begin{array}{c}\text { Faktor } \\
\text { Ekonomi }(C) \\
(0,130)\end{array}$ & $\begin{array}{l}\text { - Manfaat } \\
\text { - Estimasi Biaya Proyek }\end{array}$ & $\begin{array}{l}\mathrm{c}_{1}(0,800) \\
\mathrm{c}_{2}(0,200)\end{array}$ \\
\hline
\end{tabular}

dibandingkan dengan faktor ekonomi karena volume lalu lintas di beberapa jalan provinsi yang ada di Kabupaten Purwakarta cukup padat terutama pada jam masuk atau pulang kerja. Di samping itu truk-truk dengan tonase besar juga sering melintas untuk mengangkut barang-barang industri dari dan ke daerah kawasan industri yang ada di Kabupaten Purwakarta.

Dengan cara yang sama hal ini dilakukan terhadap sub kriteria, sehingga apabila dirangkum secara keseluruhan, akan terlihat seperti pada Gambar 2.

\section{Perhitungan Urutan Prioritas Penanganan Jalan Provinsi}

Penentuan urutan prioritas penanganan ruas jalan dengan menggunakan model matematis menurut Brojonegoro (1991), yaitu:

$\mathrm{Y}=\mathrm{A}\left(\mathrm{a}_{1} \mathrm{x} \mathrm{X}_{1}+\ldots+\mathrm{a}_{6} \mathrm{x} \mathrm{X}_{6}\right)+\mathrm{B}\left(\mathrm{b}_{1} \mathrm{x}\right.$ $\left.\mathrm{X}_{7}+\ldots \mathrm{b}_{7} \mathrm{x} \mathrm{X}_{13}\right)+\mathrm{C}\left(\mathrm{c}_{1} \times \mathrm{X}_{14}+\mathrm{c}_{2} \times \mathrm{X}_{15}\right)$

Dengan :
Y $=$ Skala Prioritas

Penanganan Jalan

A s/d C = Bobot kriteria Level 2 (berdasar analisis responden)

$\mathrm{a}_{1}, \mathrm{a}_{2}, \mathrm{a}_{3} \ldots \mathrm{c}_{2}=$ Bobot alternatif level 3 (berdasar analisis responden)

$\mathrm{X}_{1}, \mathrm{X}_{2}, \ldots, \mathrm{X}_{15}=$ Bobot alternatif level 3 (berdasar analisis data sekunder)

Dari hasil perhitungan dengan model matematis untuk menentukan urutan prioritas penanganan ruas jalan pada jaringan jalan provinsi di Kabupaten Purwakarta diperoleh persamaan sebagai berikut:

$\mathrm{Y}=0,687\left\{\left(0,363 \times \mathrm{X}_{1}\right)+\left(0,274 \times \mathrm{X}_{2}\right)+\right.$ $\left(0,131 \times \mathrm{X}_{3}\right)+\left(0,080 \times \mathrm{X}_{4}\right)+(0,061 \mathrm{x}$ $\left.\left.\mathrm{X}_{5}\right)+\left(0,091 \mathrm{x}_{6}\right)\right\}+0,183\left\{\left(0,284 \mathrm{x}_{7}\right)\right.$ $+\left(0,211 \mathrm{x} \mathrm{X}_{8}\right)+\left(0,160 \mathrm{x} \mathrm{X}_{9}\right)+(0,116 \mathrm{x}$ $\left.\mathrm{X}_{10}\right)+\left(0,114 \times \mathrm{X}_{11}\right)+\left(0,073 \times \mathrm{X}_{12}\right)+$ $\left.\left(0,042 \times \mathrm{X}_{13}\right)\right\}+0,130\left\{\left(0,800 \times \mathrm{X}_{14}\right)+\right.$ $\left.\left(0,200 \times \mathrm{X}_{15}\right)\right\}$

Persamaan model matematis di atas, selanjutnya dapat diaplikasikan pada pelaksanaan penentuan urutan 
Tabel 8 Rekapitulasi Hasil Perhitungan Bobot Sub Kriteria Data Simulasi

\begin{tabular}{|c|c|c|c|c|c|c|c|c|c|c|c|c|c|c|c|}
\hline \multirow{3}{*}{$\begin{array}{l}\text { Nama } \\
\text { Jalan }\end{array}$} & \multicolumn{15}{|c|}{ Bobot Sub Kriteria (Data Simulasi) } \\
\hline & \multicolumn{6}{|c|}{ Kondisi Jalan (a) } & \multicolumn{7}{|c|}{ Volume Lalu Lintas (b) } & \multicolumn{2}{|c|}{$\begin{array}{l}\text { Ekonomi } \\
\text { (c) }\end{array}$} \\
\hline & $\mathrm{X}_{1}$ & $\mathrm{X}_{2}$ & $\mathrm{X}_{3}$ & $\mathrm{X}_{4}$ & $\mathrm{X}_{5}$ & $\mathrm{X}_{6}$ & $\mathrm{X}_{7}$ & $\mathrm{X}_{8}$ & $\mathrm{X}_{9}$ & $\mathrm{X}_{10}$ & $\mathrm{X}_{11}$ & $\mathrm{X}_{12}$ & $\mathrm{X}_{13}$ & $\mathrm{X}_{14}$ & $\mathrm{X}_{15}$ \\
\hline A & 0,250 & 0,250 & 0,500 & 0,500 & 0,500 & 0,250 & 0,037 & 0,078 & 0,178 & 0,168 & 0,274 & 1,000 & 0,106 & 0,796 & 0,794 \\
\hline $\mathrm{B}$ & 0,500 & 0,500 & 0,250 & 0,500 & 0,250 & 0,500 & 0,034 & 0,047 & 0,112 & 0,100 & 0,209 & 0,941 & 0,072 & 0,557 & 0,474 \\
\hline $\mathrm{C}$ & 0,250 & 0,250 & 0,500 & 0,250 & 0,500 & 0,250 & 0,019 & 0,037 & 0,150 & 0,140 & 0,162 & 0,925 & 0,090 & 1,000 & 1,000 \\
\hline
\end{tabular}

prioritas penanganan ruas jalan pada jaringan jalan provinsi dengan menggunakan data kondisi jalan, volume lalu lintas, dan ekonomi.

Contoh rekapitulasi data hasil perhitungan besaran bobot sub kriteria data sekunder berdasarkan data simulasi diperlihatkan pada Tabel 8. Maka Penentuan Skala Prioritas Penanganan Jalan Provinsi dengan Metode AHP adalah

$$
\begin{aligned}
& \text { 1. Ruas Jalan A } \\
& \mathrm{Y}_{\mathrm{A}}=0,687\{(0,363 \times 0,250)+(0,274 \times \\
& 0,250)+(0,131 \times 0,500)+(0,080 \times \\
& 0,500)+(0,061 \times 0,500)+(0,091 \times \\
& 0,250)\}+0,183\{(0,284 \times 0,037)+ \\
& (0,211 \times 0,078)+(0,160 \times 0,178)+ \\
& (0,116 \times 0,168)+(0,114 \times 0,274)+ \\
& (0,073 \times 1,000)+(0,042 \times 0,106)\}+ \\
& 0,130\{(0,800 \times 0,796)+(0,200 \times \\
& 0,794)\} \\
& \mathrm{Y}_{\mathrm{A}}=0,339
\end{aligned}
$$

Selanjutnya dengan cara yang sama diperoleh nilai bobot:

2. Ruas Jalan B

$\mathrm{Y}_{\mathrm{B}}=0,474$

3. Ruas Jalan C

$\mathrm{Y}_{\mathrm{C}}=0,378$

Jadi urutan prioritas penanganan ruas jalan provinsi adalah ruas jalan $B$ menempati prioritas pertama, kemudian ruas jalan $\mathrm{C}$, dan prioritas terakhir adalah ruas jalan $\mathrm{A}$.

\section{E. KESIMPULAN DAN SARAN}

\section{Kesimpulan}

Berdasarkan hasil analisis maka dapat diambil beberapa kesimpulan sebagai berikut :

1. Hasil analisis menggunakan kombinasi metode Delphi dengan metode Cut Off Point diketahui bahwa kriteria yang akan digunakan dalam menentukan prioritas penanganan ruas jalan provinsi adalah faktor kondisi jalan, faktor volume lalu lintas, dan faktor ekonomi. Faktor kepadatan penduduk, faktor tata guna lahan dan faktor kebijakan eksekutif dianggap kurang berpengaruh dalam penentuan prioritas penanganan jalan provinsi di Kabupaten Purwakarta.

2. Hasil analisis kriteria dengan metode $A H P$, menunjukkan bahwa bobot kriteria yang paling tinggi adalah faktor kondisi jalan dengan bobot sebesar 68,7\%; disusul dengan faktor volume lalu lintas sebesar 18,3\%; sedangkan yang paling rendah adalah faktor ekonomi sebesar $13,0 \%$.

3. Sub kriteria faktor kondisi jalan memperlihatkan bahwa jalan yang berlubang memberikan bobot penilaian terbesar yaitu $36,3 \%$. Kontribusi berikutnya diberikan oleh jalan dengan legokan/amblas dengan bobot 27,4\%; 
retak-retak dengan bobot 13,1\%; drainase dengan bobot $9,1 \%$; alur bekas roda dengan bobot $8,0 \%$; dan terakhir kemiringan jalan dengan bobot $6,1 \%$.

4. Sub kriteria volume lalu lintas memperlihatkan bahwa jalan yang dilalui Truk 6 Sumbu memiliki pengaruh yang paling penting yaitu dengan bobot 28,4\%; kemudian disusul dengan Truk 5 Sumbu dengan bobot $21,1 \%$; Truk 4 Sumbu dengan bobot 16\%; Truk 3 Sumbu dengan bobot 11,6\%; Bus dengan bobot 11,4\%; selanjutnya Mobil Penumpang dengan bobot $7,3 \%$; dan terakhir Sepeda Motor dengan bobot $4,2 \%$.

5. Sub kriteria ekonomi memperlihatkan bahwa faktor manfaat memberikan kontribusi terbesar dalam penentuan prioritas penanganan jalan yaitu dengan bobot $80,0 \%$ dibandingkan biaya kegiatan proyek dengan bobot $20,0 \%$.

6. Diperoleh model persamaan matematis untuk menentukan urutan prioritas penanganan jalan pada jaringan ruas jalan provinsi di Kabupaten Purwakarta berdasarkan metode $A H P$, yaitu :

$\mathrm{Y}=0,687\left\{\left(0,363 \times \mathrm{X}_{1}\right)+\left(0,274 \times \mathrm{X}_{2}\right)\right.$ $+\left(0,131 \times X_{3}\right)+\left(0,080 \times X_{4}\right)+(0,061 \times$ $\left.\left.\mathrm{X}_{5}\right)+\left(0,091 \mathrm{x} \mathrm{X}_{6}\right)\right\}+0,183\left\{\left(0,284 \mathrm{x} \mathrm{X}_{7}\right)\right.$ $+\left(0,211 \times X_{8}\right)+\left(0,160 \times X_{9}\right)+(0,116 \times$ $\left.\mathrm{X}_{10}\right)+\left(0,114 \times \mathrm{X}_{11}\right)+\left(0,073 \times \mathrm{X}_{12}\right)+$ $\left.\left(0,042 \times X_{13}\right)\right\}+0,130\left\{\left(0,800 \times X_{14}\right)+\right.$ $\left.\left(0,200 \times X_{15}\right)\right\}$

\section{Saran}

Dari hasil penelitian dan pembahasan yang telah diperoleh, maka dapat diberikan beberapa saran terkait dengan penentuan prioritas penanganan jalan provinsi, sebagai berikut:

a. Perlu dilakukan penelitian dengan lokasi studi yang lebih luas meliputi seluruh jalan-jalan provinsi yang ada di Provinsi Jawa Barat.

b. Perhitungan untuk penentuan urutan prioritas penanganan ruas jalan provinsi sebaiknya menggunakan data fakta hasil survey lapangan.

\section{DAFTAR PUSTAKA}

Brodjonegoro, P.S, 1991, Petunjuk Mengenai Teori dan Aplikasi dari Model Then Analytic Hierarchy Process, Sapta Utama, Jakarta.

Dirjen Perhubungan Darat, 2005, Peraturan Pemerintah No.26 tahun 1985, tentang Jalan, Departemen Perhubungan Republik Indonesia, Jakarta

Peraturan Pemerintah Republik Indonesia No.34 tahun 2006 tentang Jalan, Jakarta

Tam, M.C.Y dan V.M.R.T Tummala, 2001, An Application of the AHP in Vendor Selection of a Telecomunications System, Omega, Bangkok. 